\title{
Influence of the products of phospholipolysis of phosphatidylcholine on micellar solubilization of fatty acids in the presence of bile salts
}

\author{
By A. K. LOUGH AND A. SMITH \\ Rowett Research Institute, Bucksburn, Aberdeen $A B 2$ $9 S B$ \\ (Received 7 April 1975 - Accepted 8 May 1975)
}

\begin{abstract}
r. The solubility of fatty acids in aqueous solutions containing bile salts and lysolecithin at $\mathrm{pH}$ values between 2.0 and 7.4 was studied. Both the $\mathrm{r}$-acyl and $\mathbf{z}$-acyl isomers of lysolecithin increased the solubility of fatty acids to the same extent, the order of solubility being linoleic $>$ oleic $>$ elaidic $>$ palmitic $>$ stearic.

2. The influence of the products of phospholipolysis of lecithin on palmitic acid solubility was determined. On a molar basis, lysolecithin was more effective than were bile salts in promoting the solubilization of the fatty acid.

3. In bile salt solutions in which the phospholipid concentration was constant on a molar basis, the solubility of palmitic acid decreased linearly with the progressive replacement of lecithin by lysolecithin. Palmitic acid was solubilized to the same extent on replacing lecithin with lysolecithin on a constant weight basis.

4. In bile salt solution containing lysolecithin and oleic acid in equimolar amounts, the solubility of palmitic acid was similar to that in bile salt solutions containing lecithin in equivalent proportion.

5. The results are discussed in relation to the action of phospholipolytic activity on the intestinal absorption of fatty acids in sheep.
\end{abstract}

In the small intestine of adult sheep fed on a normal diet, lecithin is progressively hydrolysed by pancreatic phospholipases to lysolecithin with the concomitant release of mainly octadecenoic acids (Lennox \& Garton, 1968; Arienti, Leat \& Harrison, 1975). The site of optimal absorption of unesterified fatty acids in the sheep is in the middle and lower jejunum, in which lysolecithin is the main phospholipid component of the intestinal contents. As a continuation of the studies reported in the previous paper (Smith \& Lough, 1976) on the maximal solubilization of fatty acids by bile components, the influence of lysolecithin as an adjuvant to bile salts on the micellar solubilization of the principal fatty acids of sheep intestinal digesta was studied.

Since the uptake and dissimilation of phospholipid are virtually complete by the time the digesta reach the ileum (Lennox \& Garton, 1968), oleate which is released as a consequence of phospholipolysis of lecithin may be an additional amphiphile in the solubilization of fatty acids. Thus, the micellar solubility of fatty acids in solutions containing bile salts, I-acyllysolecithin and oleic acid was studied. The influence of 2-acyllysolecithin on the solubility of palmitic acid in bile salt solution was also studied. 
Table I. Component fatty acids $(\mathrm{mg} / \mathrm{g})$ of $\mathrm{I}$-acyllysolecithin isolated from egg lecithin and of 2-acyllysolecithin isolated from crude egg oil*

$\begin{array}{ccc}\text { Fatty acid } & \text { r-Acyllysolecithin } & \text { 2-Acyllysolecithin } \\ \text { 16:0 } & 566 & 78 \\ \text { 16:1 } & 23 & 25 \\ \text { 18:0 } & 278 & 34 \\ \text { 18:1 } & 75 & 679 \\ \text { 18:2 } & 39 & 112 \\ 20: 4 & 20 & 69\end{array}$

* For details of experimental procedures, see below

EXPERIMENTAL

Materials

I $-^{14} \mathrm{C}$-labelled fatty acids and $\left[9,10-{ }^{3} \mathrm{H}\right]$ oleic acid were purchased from the Radiochemical Centre, Amersham, Bucks. Unlabelled fatty acids were purchased either from Sigma Chemical Co. Ltd, London or from Price's Chemicals Ltd, Wirral, Cheshire.

Mixed bile salts were isolated from sheep gall-bladder bile by the method of Smith, Anderson \& Lough (1973). Lysolecithin (I-acyl) was obtained by the action of phospholipase $\mathrm{A}_{2}(E C 3 . \mathbf{r} \cdot \mathbf{I} \cdot 4)$, from Crotalus adamanteus, on purified egg lecithin according to the method of Long \& Penny (1957). Lysolecithin (2-acyl) was isolated from crude egg oil. As the 2-acyl isomer was purified by silicic-acid column chromatography some isomerization of the acyl groups is likely to have taken place (Slotboom, De Haas \& Van Deenen, 1967). Therefore, the isolated lysolecithin must be presumed to be a mixture of both the I-acyl and 2-acyl isomers. The fatty acid composition of the isolated lysolecithins is shown in Table $I$.

The purity of the lysolecithins and of the isolated bile salts was checked by thinlayer chromatography using the solvents and spray reagents described previously (Smith \& Lough, 1976).

\section{Methods}

The solubility of fatty acids in aqueous solutions of bile salts and lysolecithin was determined using the method described by Smith \& Lough (1976).

\section{RESULTS}

Influence of lysolecithin on the solubility of long-chain fatty acids in aqueous solutions of bile salts

Amphiphilic indices (Freeman, 1969) were calculated from the solubility of fatty acids in micellar solutions containing ro mmol bile salts $/ 1$ and up to $2 \mu \mathrm{mol} \mathrm{r}$-acyllysolecithin/ml over the $\mathrm{pH}$ range $2 \cdot 0-7 \cdot 4$ and the values are given in Table 2 . The results indicate that the solubility of each fatty acid increased with increasing $\mathrm{pH}$ of the micellar solutions, although at $\mathrm{pH} 2 \cdot 0$ the addition of lysolecithin did not appear to influence the solubility of saturated fatty acids. The solubility of saturated fatty 
Table 2. Effect of $p H$ on the amphiphilic index (ratio, increase in solubility ( $\mu \mathrm{mol}): \mu \mathrm{mol}$ lysolecithin added (Freeman, 1969)) of fatty acids in solutions containing bile salts and I-acyllysolecithin at $37^{\circ *}$

\begin{tabular}{lllll} 
& \multicolumn{4}{c}{ pH } \\
Fatty acid & 2.0 & 4.0 & 6.0 & 7.4 \\
Palmitic & 0.00 & 0.29 & 0.40 & 0.62 \\
Stearic & 0.00 & 0.11 & 0.12 & $0.3 \mathrm{r}$ \\
Oleic & 1.00 & 1.34 & 1.67 & nd \\
Elaidic & 0.34 & 0.64 & 1.02 & nd \\
Linoleic & 1.66 & 1.65 & 2.49 & nd
\end{tabular}

nd, Not determined.

* For details of experimental procedures, see p. 90 and Smith \& Lough (1976).

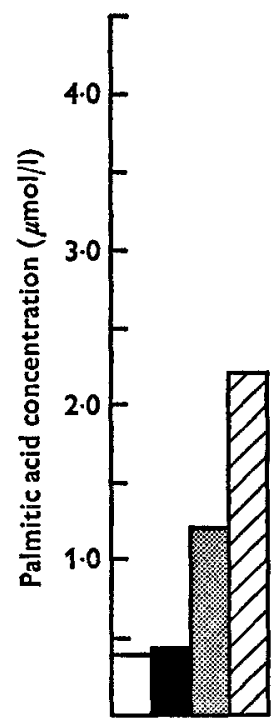

Bile salts

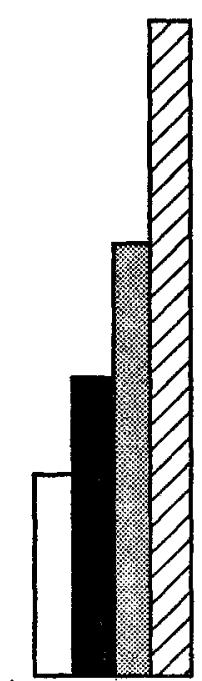

1-Acyllysolecithin 2-Acyllysolecithin

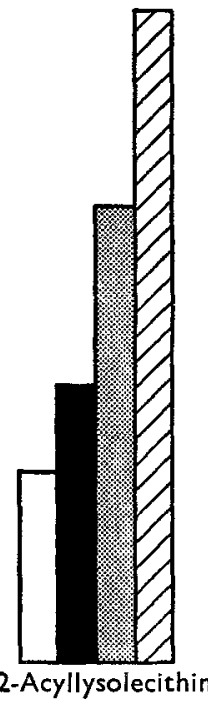

Fig. I. Effect of aqueous solutions containing $10 \mathrm{mmol}$-acyllysolecithin, 2-acyllysolecithin or bile salts $/ 1$ on the solubilization of palmitic acid at $37^{\circ} . \square, \mathrm{pH} 2 \cdot 0 ; \mathbf{1}, \mathrm{pH} 44^{\circ}$; 国, $\mathrm{pH}, 6 \cdot 0 ; \square, \mathrm{pH} 7 \cdot 4$. For details of experimental procedures, see p. 90 and Smith \& Lough (1976).

acids in bile salt-2-acyllysolecithin micellar solution was exactly similar to that in aqueous solutions containing bile salts and I-acyllysolecithin (Smith, 1974). Furthermore, the results indicate that, in contrast to saturated fatty acids, unsaturated fatty acids were readily solubilized at $\mathrm{pH} 2 \cdot 0$ in the presence of lysolecithin in bile salt solution.

Over the $\mathrm{pH}$ range $2 \cdot 0-7 \cdot 4$ the solubility of the fatty acids was in the order linoleic $>$ oleic $>$ elaidic $>$ palmitic $>$ stearic. 


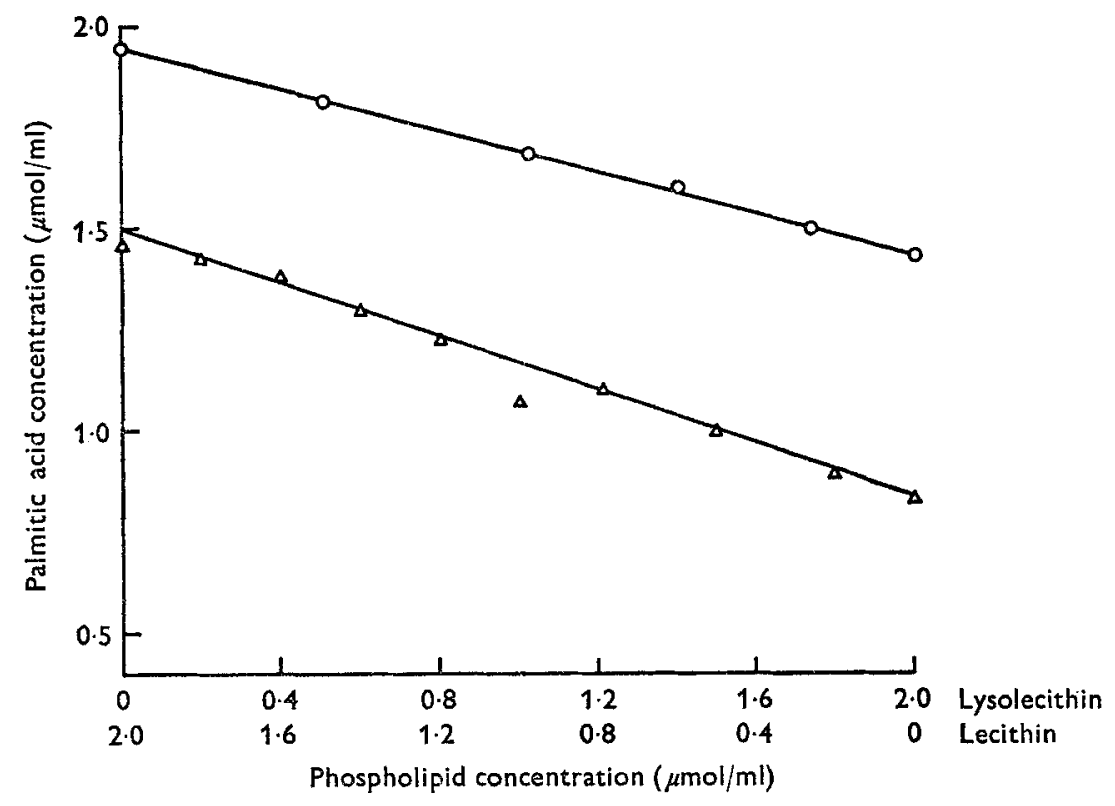

Fig. 2. Effect of the progressive replacement of lecithin with equimolar proportions of lysolecithin on the solubilization of palmitic acid in an aqueous solution of $10 \mathrm{mmol}$ bile salts/l at $37^{\circ} . \triangle, \mathrm{pH}_{4}^{\circ} \circ ; \mathrm{O}, \mathrm{pH} 6.0$. For details of experimental procedure, see p. 90 and Smith $\&$ Lough (1976).

Interaction of the products of phospholipolysis on the micellar solubilization of long-chain fatty acids in aqueous solutions of bile salts: solubility of palmitic acid in aqueous solutions of lysolecithin

The maximum solubility of palmitic acid in aqueous solutions of $\mathrm{I}$-acyllysolecithin and of 2-acyllysolecithin is shown in Fig. 1. For comparative purposes, the solubility of the fatty acid in aqueous solutions of bile salt is included. The concentrations of both bile salts and lysolecithin were ro $\mathrm{mmol} / \mathrm{l}$.

The results indicated that in the absence of bile salts, palmitic acid was solubilized to an equal extent by the $x$-acyl and 2-acyl isomers. Relative to the solubilization of fatty acid in bile salt solution, the uptake of fatty acid into micellar solutions of lysolecithin was about three times greater at $\mathrm{pH} 2 \cdot 0$ and twice as great at $\mathrm{pH} 7 \cdot 4$.

\section{Influence of constant molar and constant weight ratios of lecithin and lysolecithin on the solubility of palmitic acid in bile salt solutions}

Previous results (Fig. I) indicated that lysolecithin is an effective amphiphile for the solubilization of palmitic acid. Progressive hydrolysis of lecithin causes the phospholipid content of sheep intestinal digesta to vary from predominantly lecithin in the upper jejunum to lysolecithin in the middle and lower jejunum. Thus, in certain regions of the jejunum lysolecithin is likely to be in admixture with lecithin and bile salts. Therefore, the solubility of palmitic acid in bile salt solutions containing certain lecithin:lysolecithin ratios on a constant molar basis $(2 \mu \mathrm{mol} / \mathrm{ml})$ and on a 


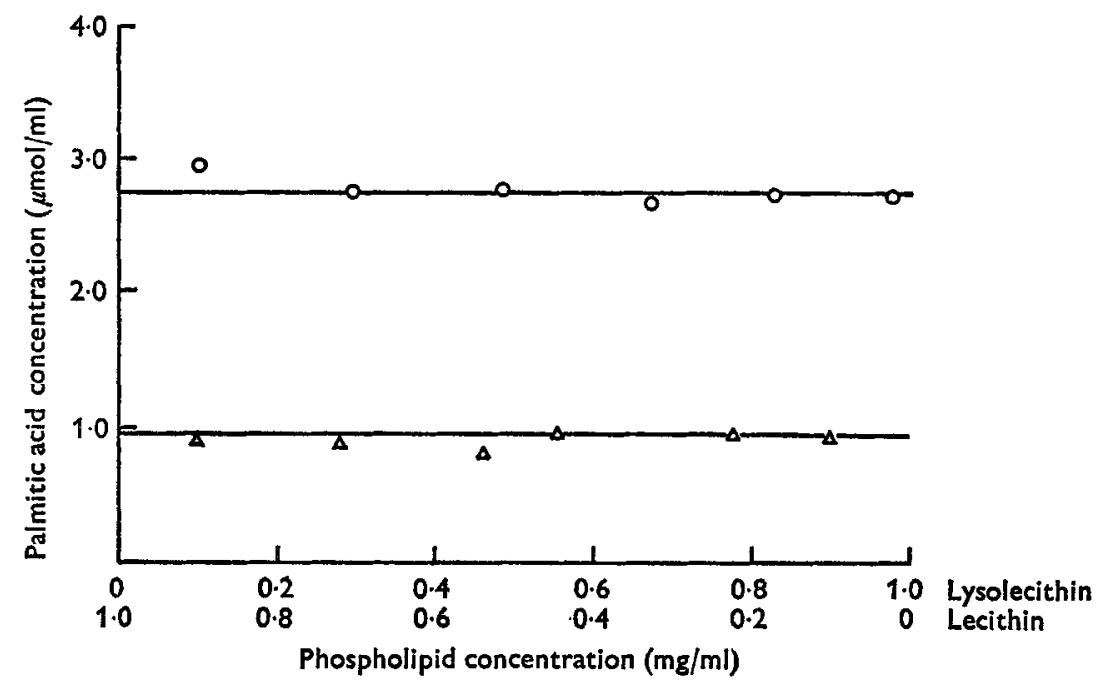

Fig. 3. Effect of the progressive replacement of lecithin with an equal weight of lysolecithin on the solubilization of palmitic acid in an aqueous solution of $10 \mathrm{mmol}$ bile salts $/ 1$ at $37^{\circ}$. $\triangle, \mathrm{pH}_{4} \cdot 0 ; \mathrm{O}, \mathrm{pH} 6 \cdot 0$. For details of experimental procedures, see p. 90 and Smith \& Lough (1976).

constant weight basis $(\mathrm{I} \mathrm{mg} / \mathrm{ml}$ ) was studied over the $\mathrm{pH}$ range $2 \cdot 0-7 \cdot 4$; the bile salt concentration was constant at Io $\mathrm{mmol} / \mathrm{l}$. The solubility curve for palmitic acid in bile salt solution at $\mathrm{pH} 4.0$ and 6.0 in which the phospholipid concentration was constant on a molar basis is shown in Fig. 2 while that in which the phospholipid concentration was constant on a weight basis is shown in Fig. 3 .

When the phospholipid concentration was constant on a molar basis, the solubility of palmitic acid in bile salt solution at $\mathrm{pH}_{4.0}$ and 6.0 decreased linearly as the relative amounts of phospholipid were varied from lecithin alone to lecithin-lysolecithin mixtures and to lysolecithin alone. However, when the phospholipid concentration was constant on a weight basis, the solubility of palmitic acid was not affected by the presence of lecithin or lysolecithin or both as the amphiphile. Similar trends were evident for the solubility of palmitic acid at $\mathrm{pH} 2 \cdot 0$ and $7 \cdot 4$ and for that of stearic acid over the $\mathrm{pH}$ range $2 \cdot 0-7 \cdot 4$.

\section{Influence of the products of phospholipolysis of lecithin on long-chain fatty acid solubility in aqueous solutions of bile salts}

The main fatty-acyl group released from the hydrolysis of lecithin in the intestinal lumen of the sheep is oleate. Consequently, the effect of oleate in admixture with lysolecithin, in bile salt solution, on the solubility of palmitic acid and stearic acid over the $\mathrm{pH}$ range $4^{\cdot 0-} 7^{\cdot 4}$ was studied. The results indicated that bile salt solutions containing I-acyllysolecithin and oleic acid in equimolar proportion effected the solubilization of these saturated fatty acids to the same extent as did lecithin in equivalent concentration (Smith, 1974). 


\section{DISCUSSION}

The findings from the present study have indicated that lysolecithin, as an additive to bile salts in aqueous media, is broadly similar to lecithin in its influence on the solubilization of long-chain fatty acids. In bile salt solution at $\mathrm{pH} 4^{\circ} \circ$ and 6.0 it was found that, weight-for-weight, lysolecithin solubilized palmitic acid to the same extent as did lecithin. The marked increase in the solubilization of saturated fatty acids that occurred with an increase in $\mathrm{pH}$ of the bile salt-lecithin micellar solution was also evident in the corresponding bile salt-lysolecithin system.

However, the influence of the monoacyl phospholipid on the uptake of octadecenoic acid into micellar solution differed from that of lecithin, in that above $\mathrm{pH} 4^{\circ} \circ$ both cis- and trans- forms of the monounsaturated acid contributed to micelle formation, whereas in the presence of lecithin a competitive effect has been noted (Smith \& Lough, 1976). Also, at $\mathrm{pH} 2 \cdot 0$, lysolecithin had apparently no effect on the incorporation of saturated fatty acids into mixed micelles with bile salts, whereas lecithin added to bile salts solubilized an appreciable amount of fatty acid.

The extent of incorporation of fatty acid into mixed micelles comprising bile salts and lysolecithin was apparently unchanged when lysolecithin which consisted mainly of the palmitoyl ester was replaced by a sample of lysolecithin in which the fatty acid moiety was principally oleyl.

Earlier workers have found that the presence of oleic acid, in ionized or partially ionized forms, promotes the solubilization of long-chain saturated fatty acids in aqueous media containing bile salts (Savary, 1966; Freeman, 1969). However, as an additive to bile salts, fully protonated oleic acid has little effect on the solubilization of palmitic acid and stearic acid, the amphiphilic indices being 0.08 and 0.06 respectively at $\mathrm{pH} 4^{\circ} \circ$ (Smith, I974).

As an additive to mixed micelles containing bile salts and lysolecithin, oleic acid had very marked effects on the solubilization of fatty acids over a wide $\mathrm{pH}$ range. In particular, it was noted that bile salt micelles containing I-acyllysolecithin and oleic acid in equimolar proportions incorporated palmitic acid to the same extent, over the $\mathrm{pH}$ range $4^{\cdot 0-7 \cdot 4}$, as did those containing an equivalent proportion of lecithin. Similarly, bile salt solutions containing either lysolecithin and oleic acid or lecithin in equivalent concentration solubilized cholesterol to the same extent (Neiderhiser \& Roth, 1972).

Unsaturated and saturated fatty acids are readily solubilized in bile salt solutions in the presence of lysolecithin, therefore it would appear that absorption from the lumen of the small intestine of the sheep could readily occur from a bile saltlysolecithin micellar solution, particularly at $\mathrm{pH}$ values about $4^{\circ} \mathrm{O}$. Although lysolecithin is a more effective amphiphile than bile salts for the solubilization of saturated fatty acids, it is unlikely that micellar structures comprising only lysolecithin exist in the jejunal lumen of the sheep, since the concentration of bile salts in the aqueous phase is of the order of $10 \mathrm{mmol} / \mathrm{l}$, about twenty times that of lysolecithin (Lennox, Lough \& Garton, 1968).

Uptake of the lipid constituents of digesta from the small intestine of the sheep is 
markedly impaired when either bile secretion or pancreatic secretion is diverted from the small intestine (Heath \& Morris, I963; Heath \& Hill, i969; Leat \& Harrison, 1969). Furthermore, these secretions in admixture convert lecithin (of biliary origin) to lysolecithin and unesterified fatty acid (mainly oleic acid). In relation to the present results, it would appear that the action of phospholipolysis on a given amount of lecithin in the presence of bile salts is unlikely to lead to any change in the extent to which unesterified fatty acids can be taken into micellar solution. However, the solubilization studies described here concern conditions at equilibrium and do not give any indication of the rate at which solubilization may occur. Moreover, some account should be taken of the fact that the uptake of fatty acids into micellar solution in the lumen contents of the small intestine of sheep involves a mechanism of solubilization which necessarily includes removal of the fatty acids from association with the solid matter of the digesta.

The process whereby unesterified, long-chain fatty acids are released from association with the particulate matter of sheep intestinal digesta apparently involves detergency (Lough, 1970; Scott \& Lough, 197I). In this context, the theory of polar detergency proposed by Lawrence $(196 \mathrm{r} a, b)$ is probably relevant because it affords an explanation for the dissolution of fatty acids of high melting-point in aqueous media at ordinary temperatures. The mechanism of polar detergency is complex but essentially comprises the highly-localized formation of a liquid-crystalline phase which results from the interaction of fatty acid, surface-active compound (detergent) and water; the mesophase thus formed is dispersed as mixed micelles in the detergent solution (Lawrence, $196 \mathrm{I} a, b$ ). It can therefore be envisaged that unesterified fatty acid is transferred from association with the solid matter of digesta into micellar solution in the intestinal lumen of sheep initially by interaction of fatty acid, phospholipid and water, resulting in the incorporation of fatty acid into a liquid-crystalline phase that is thereafter dispersed in the presence of bile salts to form a micellar solution (Lough, 1970).

In terms of the over-all process of detergency in the lumen contents of the small intestine of sheep, the particulate matter of the digesta can presumably be regarded as an inert support to which fatty acids are attached, because polar detergency functions in a manner that is independent of the surfaces with which the fatty acids are associated (Lawrence, 1961 $a, b$ ). Fatty acids of sheep intestinal digesta will therefore be solubilized at a rate that depends on the extent to which they are dispersed on the particulate matter; the fatty acids, which are fully protonated and are apparently not in the form of a complex with the structural components of the digesta, implicitly exist in a high extent of dispersion which will greatly favour their uptake into mixed micelles with bile salts and phospholipids (Lough, 1970; Smith \& Lough, 1973).

However, the possibility exists that by converting lecithin to lysolecithin and unesterified fatty acid, phospholipolytic activity will also influence the rate at which fatty acids are taken into micellar solution. But the results of the present investigation have shown that replacement of lecithin with equimolar proportions of lysolecithin and oleic acid as additives with bile salts apparently does not affect the amount of saturated fatty acid solubilized. It would therefore seem likely that the influence of 
phospholipolysis on the absorption of fatty acids from the small intestine is of importance mainly in the uptake of micellar lipid by the intestinal mucosal cells. In this connexion, it is noteworthy that the results of studies on non-ruminant animals have indicated that lecithin is apparently not absorbed intact whereas I-acyllysolecithin and unesterified fatty acid are readily assimilated by the intestinal mucosal cells (Scow, Stein \& Stein, I967; Nilsson, I968).

The authors wish to thank Dr G. A. Garton for his helpful criticism of the manuscript, Mrs J. A. Anderson for her technical assistance, and Dr J. Patterson, Department of Biochemistry, University of Strathclyde, Glasgow, for his generous gift of crude egg oil.

\section{REFERENCES}

Arienti, G., Leat, W. M. F. \& Harrison, F. A. (1975). Q. $尹$ l exp. Physiol. 6o, 5.

Freeman, C. P. (1969). Br. F. Nutr. 23, 249.

Heath, T. J. \& Hill, L. N. (1969). Aust. F. biol. Sci. 22, 101 5.

Heath, T. J. \& Morris, B. (1963). Br. F. Nutr. I7, 465.

Lawrence, A. S. C. (I96I $a$ ). In Surface Activity and Detergency, p. I 58 [K. Durham, editor]. London: Macmillan.

Lawrence, A. S. C. (196r b). Chemy Ind. p. 1764 .

Leat, W. M. F. \& Harrison, F. A. (1969). Q. $\mathscr{~ I l ~ e x p . ~ P h y s i o l . ~ 5 4 , ~} 187$.

Lennox, A. M. \& Garton, G. A. (1968). Br. F. Nutr. 22, 247.

Lennox, A. M., Lough, A. K. \& Garton, G. A. (1968). Br. F. Nutr. 22, 237.

Long, C. \& Penny, I. F. (r957). Biochem. F. 65, 382.

Lough, A. K. (I970). In Physiology of Digestion and Metabolism in the Ruminant, p. 5 I9 [A. T. Phillipson, editor]. Newcastle upon Tyne: Oriel Press.

Neiderhiser, P. W. \& Roth, H. P. (1972). Biochim. biophys. Acta 270, 407.

Nilsson, A. (1968). Biochim. biophys. Acta 152, 379.

Savary, P. (1966). Biochim. biophys. Acta 125, 328.

Scott, A. M. \& Lough, A. K. (197I). Br. F. Nutr. 25, 307.

Scow, R. O., Stein, Y. \& Stein, O. (1967). J. biol. Chem. 242, 49 rg.

Slotboom, A. J., De Haas, G. H. \& Van Deenen, L. L. M. (1967). Chem. Phys. Lipids r, 317.

Smith, A. (1974). Aspects of micellar solubilization of fatty acids by biliary components in relation to lipid digestion in the sheep. PhD Thesis, University of Aberdeen.

Smith, A., Anderson, L. J. \& Lough, A. K. (I973). Chemy Ind. p. 484.

Smith, A. \& Lough, A. K. (1973). Proc. Nutr. Soc. 32, 62A.

Smith, A. \& Lough, A. K. (1976). Br. F. Nutr. 35, 77. 